\title{
O ENSINO DA EDUCAÇÃO FINANCEIRA NO ENSINO FUNDAMENTAL II
}

\author{
Adelmo Santos Brito ${ }^{1}$ \\ Augêncio Antunes dos Santos Junior ${ }^{2}$
}

\section{Resumo}

Este artigo tem como objetivo abordar sobre o ensino da Educação Financeira no Ensino Fundamental II destacando a importância da mesma nesse segmento. A elaboração da Base Nacional Comum Curricular - BNCC incluiu a matemática financeira com a finalidade de proporcionar condições para 0 individuo desenvolvesse habilidades de gerir de modo consciente a vida financeira do cidadão. Através da pesquisa bibliográfica foi possível conhecer diversas abordagens e concepções sobre 0 assunto pesquisado. Nesta pesquisa foram escolhidos artigos completos, dissertações e teses que foram analisados através da leitura dos mesmos com foco em categorias prévias a fim de responder ao objetivo proposto, a saber. Pode-se afirmar que a educação financeira beneficia os indivíduos no sentido de protegê-lo para rentabilizar suas economias, pois é imperativo que se tenha uma boa formação como investidor pessoal e se preocupar com a rentabilidade, risco e liquidez de cada opção disponível no mercado.

Palavras Chaves: Educação Financeira. Matemática. Ensino Fundamenta II.

\begin{abstract}
This article aims to address the teaching of Financial Education in Elementary Education II, highlighting its importance in this segment. The elaboration of the National Common Curricular Base - BNCC included financial mathematics in order to provide conditions for the individual to develop skills to consciously manage the financial life of the citizen. Through bibliographic research it was possible to know different approaches and conceptions about the researched subject. In this research, complete articles, dissertations and theses were chosen, which were analyzed by reading them with a focus on previous categories in order to answer the proposed objective, namely. It can be said that financial education benefits individuals in order to protect them in order to profit from their savings, as it is imperative to have a good training as a personal investor and to be concerned with the profitability, risk and liquidity of each option available on the market .
\end{abstract}

Keywords: Financial Education. Mathematics. Fundamental Education II.

\footnotetext{
1 Mestre em Ciências da Educação pela Faculdade Iteramericana de Ciências Sociales (FICS). Licenciado em Matemática. Especialista em Gestão Escolar, Mídias e Educação à Distância. Professor na Rede Estadual baiana. E-mail: adelmosantosbrito@hotmail.com

2 Mestre em Ciências da Educação pela Faculdade Iteramericana de Ciências Sociales (FICS). Licenciado em Matemática. Professor na Rede Municipal de D'ávila. Email: professoraugencio@gmail.com
} 


\title{
Introdução
}

A compreensão da educação financeira via a matemática requer a inserção de recursos didáticos atrativos na prática da sala de aula, voltado para a matemática com o conteúdo compreensível para os alunos, mostrá-la que é importante para nosso dia, nas pequenas tarefas.

Proporcionar educação financeira por meio da matemática é uma tarefa que requer bastante esforço por parte do professor, pois é preciso criatividade nas aulas para que o aluno construa/internalize atitudes, valores e conceitos. Hoje existe uma movimento de consumo intenso estimulado pela sociedade e mídia, e as crianças não estão indiferente esse apelo ao consumo.

Acredita-se que o ensino da educação financeira na disciplina de matemática no Ensino Fundamental II pode contribuir para a formação de cidadãos mais críticos; educa o aluno para ser consumidor consciente; promove a formação matemática e cidadã dos alunos; contribui para ampliar a compreensão das operações fundamentais. A matemática financeira contribui para a conscientização de planejamento e gestão de renda bem como economizar, investir e afiançar uma vida financeira mais estável, pois:

\begin{abstract}
Discutir a Educação Financeira no sistema de ensino é vislumbrar a possibilidade de atingir diversos segmentos da população, tendo em vista a busca da universalização da Educação Básica. É importante ainda considerar que os estudantes podem levar questões para serem discutidas em seus lares, ampliando o alcance da proposta (CAMPOS, 2012, p. 57).
\end{abstract}

A educação financeira instiga a percepção dos indivíduos acerca da relevância realizar planos financeiros, para contrabalançar as obrigações e ensina modos de lidar com gastos e finanças. Faz-se necessário desenvolver a prática da educação financeira na sala de aula, especialmente no Ensino Fundamental para que os alunos possam ser preparados para saber lidar e trabalhar com questões reais como: consumo consciente e economia sustentável de modo bem como compreender conceitos e produtos financeiros para lidar cotidianamente com valores e desenvolver competências sobre oportunidades e riscos financeiros; conscientiza a realizar escolhas e adotar ações que melhorem o bem-estar.

\section{A Educação Financeira e Base Nacional Comum Curricular (BNCC)}

A proposta da Estratégia Nacional de Educação Financeira (ENEF) nas escolas teve como principal objetivo a educação voltada para orientação do uso 
consciente do dinheiro, cultivando hábitos e procedimentos mais apropriados para a sua saúde financeira e bem-estar social. Tal proposta parte do pressuposto que indivíduos educados financeiramente principalmente jovens podem contribuir de modo mais efetivo para a formação de uma sociedade mais responsável e comprometida com o futuro.

Preparar o aluno para o pleno exercício da cidadania comunidade exige da escola e dos seus conteúdos programáticos, contemplados nos livros didáticos, a implementação de competências e habilidades que propiciem uma atitude independente diante dos problemas a serem enfrentados.

E uma das possibilidades de preparo é por meio dos Parâmetros Curriculares Nacionais (PCN) onde encontra-se orientações para a abordagem de problemas cotidianos dos alunos, muitos dos quais relacionados, direta ou indiretamente, à situação econômica do aluno, de sua família, da escola, de sua comunidade, do seu país e até mesmo questões de caráter global (BRASIL, 1998),.

Nos PCNs de matemática, estão presentes conteúdos, habilidades e competências integradas à Matemática Financeira (MF), tanto no grupo proposto ao Tratamento da Informação quanto no grupo proposto à Álgebra, mas é nos PCNs de Temas Transversais que os problemas característicos da Educação Financeira ganham destaque, sobretudo em "Ética e Cidadania", "Meio Ambiente" e "Trabalho e Consumo".

No ano de 2014, o Ministério da Educação e Cultura (MEC) iniciou a elaboração da Base Nacional Comum Curricular (BNCC), com o objetivo e as características de um documento normativo que apresentasse as noções mínimas necessárias para o desenvolvimento de competências gerais esperadas para o pleno exercício da cidadania, para adequação ao mundo do trabalho e para a solução de questões cotidianas, de forma plena, por toda a população brasileira. $A$ BNCC é um documento de caráter normativo que:

\footnotetext{
Define o conjunto orgânico e progressivo de aprendizagens essenciais que todos os alunos devem desenvolver ao longo das etapas e modalidades da Educação Básica, que prevê que os estudantes aprendam a ler e compreender, com autonomia, boletos, faturas e carnês e destaca, dentre outras, habilidades relacionadas ao cálculo do consumo de energia elétrica de eletrodomésticos e a avaliação do impacto do uso no orçamento mensal da família (GIORDANO et al, 2019, p. 58).
}

A BNCC incluiu a Educação financeira entre os temas transversais que deverá ser introduzido nos currículos de todo o Brasil. Já no documento introdutório 
da Base Nacional Comum Curricular (BNCC), é evidente a inovação que se refere à EF e MA, pois direciona de forma objetiva que sejam trabalhadas concepções fundamentais de economia e finanças, visando à educação financeira dos alunos, elencando uma série de conteúdos básicos para discussão, tais como taxa de juros, inflação, investimentos e impostos.

A partir desse momento a Educação Financeira e à Matemática Financeira passa a fazer parte de uma lista de assuntos que devem ser inseridos na proposta pedagógicas (PP) da escola. E apesar de ser um assunto interdisciplinar, exclusivamente a base de matemática o inclui explicitamente recomendado para 0 desenvolvimento de habilidades como cálculo de juros e porcentagem.

Como apresenta o Quadro 1 a BNCC discute a Educação Financeira e de consumo nas disciplinas de Língua Portuguesa e Ciências naturais.

\begin{tabular}{|c|c|}
\hline DISCIPLINA/ÁREA & HABILIDADES \\
\hline Em Língua Portuguesa & $\begin{array}{l}\text { Uma das habilidades elencadas prevê que os estudantes aprendam } \\
\text { a ler e compreender, com autonomia, boletos, faturas e carnês. }\end{array}$ \\
\hline Ciências Naturais & $\begin{array}{l}\text { Habilidades relacionadas ao cálculo do consumo de energia elétrica } \\
\text { de eletrodomésticos e a avaliação do impacto do uso no orçamento } \\
\text { mensal da família. Tais habilidades têm o potencial de impactar } \\
\text { positivamente a saúde financeira do cidadão }\end{array}$ \\
\hline
\end{tabular}

As habilidades apresentadas no quadro acima proporcionam condições para que o indivíduo torne-se consciente e esclarecido para gerir o dinheiro e adquira novos hábitos, comportamentos e valores. As sugestões para desenvolvimento de estudos interdisciplinares abrangem as dimensões econômicas, psicológica, social, política e cultural acerca de assuntos referentes ao consumo e emprego e/ou utilização coerente do dinheiro

\section{Educação Financeira na Sala de Aula}

O governo federal implementou a Estratégia Nacional de Educação Financeira (ENEF), uma política pública para fomentar o ensino de educação financeira. Ao analisar um projeto-piloto em escolas brasileiras, o Banco Mundial constatou que os alunos tinham se tornado mais conscientes em relação às próprias finanças. Com a incorporação da educação financeira em sala de aula, após a inclusão BNCC, pais devem observar se os filhos estão discutindo dinheiro na rotina escolar. 
Trabalhar Educação Financeira na escola traz à sala de aula a interdisciplinaridade e a descrição do contexto em um processo de construção do aluno como cidadão, é a preparação do indivíduo. Principalmente, com os educandos das classes sociais mais baixas que necessita de um investimento intenso para conscientizar o educando da importância do planejamento de suas finanças, de como gerenciar o dinheiro, aprendizado em sala de aula (SILVA, 2011).

$O$ ensino da Matemática pode ser potencializado diante de diferentes ambientes de aprendizagens, cada ligado a um tipo de referência Quadro 1 que possibilitam a significação da aprendizagem de Matemática por meio dos docentes que são elas:

\section{Quadro 5 - Significação da Aprendizagem de Matemática}

\begin{tabular}{|l|l|}
\hline \multicolumn{1}{|c|}{ REFERENCIAIS } & \multicolumn{1}{|c|}{ APRENDIZAGEM } \\
\hline $\begin{array}{l}\text { Questões e atividades } \\
\text { referentes à Matemática }\end{array}$ & $\begin{array}{l}\text { São exercícios apresentados no contexto da "Matemática } \\
\text { pura }\end{array}$ \\
\hline $\begin{array}{l}\text { Questões referentes a uma } \\
\text { semi-realidade }\end{array}$ & $\begin{array}{l}\text { É quando há uma situação artificial. Ela é totalmente } \\
\text { descrita pelo texto da atividade; mais informações são } \\
\text { irrelevantes; uma semi-realidade é um mundo sem } \\
\text { impressões dos sentidos }\end{array}$ \\
\hline $\begin{array}{l}\text { Questões com referência a a } \\
\text { situações da vida real }\end{array}$ & São atividades baseadas na vida real. \\
\hline
\end{tabular}

Fonte: Silva,2011

As referências são reais, tornam possível aos alunos produzirem diferentes significados para as atividades. Os alunos terão que calcular quanto ganham, quanto gastam durante semana/mês e ver se sobra algum dinheiro ou se é preciso economizar, reduzir alguns gastos, para efetuar a compra. Para trabalhar essas questões a escola é:

Muito importante na conscientização em torno do uso do dinheiro, sobretudo nas séries finais do Ensino Fundamental e no Ensino Médio, período em que o indivíduo está adquirindo mais responsabilidade em seu meio social. E nesse período também que o aluno já domina conceitos de Matemática Financeira e Economia, itens indispensáveis para uma boa administração financeira. $O$ ensino da Matemática na escola deve seguir à vida cotidiana (SILVA, 2011, [s/p]).

Ainda sobre o ensino na sala de aula de Matemática, Skovsmose (2000) aponta dois tipos de paradigmas. O paradigma do exercício, o qual é voltado para resoluções de exercício, geralmente trazidos pelos livros didáticos e formulados por autoridades externas à sala de aula e tem como característica central a existência de apenas uma resposta certa. 


\section{O Docente de Matemática e a Educação Financeira}

Os professores fundamentaram sua posição sobre a importância dos conteúdos da matemática financeira em exemplos de situações reais nos quais o consumidor precisa ter consciência das condições que estão sendo colocadas por ocasião de uma compra à vista, a prazo e nos financiamentos. Também se manifestaram sobre a preparação para a vida e a importância nas decisões econômicas nas famílias. Além disso, externaram a preocupação com o ingresso no mercado de trabalho e o prosseguimento dos estudos.

Lidar com o conceito da matemática dos docentes, refere-se à aprendizagem, portanto ao desenvolvimento de uma prática pedagógica tendo em vista à apreensão do fato, à constituição de argumentos que possibilitem ao aluno utilizá-lo de modo lógico e conveniente na sua vida escolar e extra-escolar. Nesse sentido, aponta que:

O professor que deseja melhorar suas competências profissionais e metodologias de ensino, além da própria reflexão e atualização sobre o conteúdo da matéria ensinada, precisa estar em estado permanente de aprendizagem (KENSKI, 2003, p. 88).

Os docentes necessitam de uma capacitação permanente para conduzir as discussões sobre educação financeira para trabalhar todos os conteúdos necessários.

\section{O Discente e o Ensino da Educação Financeira}

Para o país crescer é importante que os seus cidadãos desde a sua entrada na escola sejam apresentados desde o início para as crianças, pois um cidadão que receba orientação e formação financeira desde a família sendo reforçado na escola terá recursos para evitar os apelos consumistas e pode evitar o endividamento e se sentirá mais seguro no futuro. A formação cidadã voltada para educação financeira (EF) favorece a família e o país, principalmente os mais carentes. A educação Financeira pode ser considerada como:

\footnotetext{
Um processo de transmissão de conhecimento que permite o desenvolvimento de habilidades nos indivíduos, para que eles possam tomar decisões e seguras, melhorando o gerenciamento de suas finanças pessoais (SAVOIA, AITO e SANTANA 2007, p. 2).
}

A EF inclui dar as crianças e adolescentes condições de perceberem que elas são capazes de aprenderem a lidar com o dinheiro de maneira planejada. A EF deve 
propiciar que as crianças saibam distinguir necessidades de anseios e a compreender as probabilidades limitadas que o dinheiro pode atender. É importante que as crianças tenham noção básica de dinheiro, e a relação entre pais e filhos tem uma importância significativa na educação financeira.

A educação para planejamento financeiro pode evitar o consumismo, estimular um pensamento prospectivo voltado para coletividade e o bem comum de sua família e comunidade. Hoje é muito comum ver famílias das mais diversas classes endividadas. Também vemos crianças e adolescentes em shoppings e supermercado solicitando que seus pais comprem tudo que o universo consumista oferece. É importante se preparar financeiramente, principalmente entre crianças e adolescentes, pois:

O uso da Educação Financeira concorre para o exercício da cidadania, pois proporciona as pessoas à aquisição de conhecimentos sobre como se relacionar de forma sustentável com as finanças, diminuindo os riscos de exclusão financeira (PINHO et al, 2011).

O uso da educação financeira pode estimular a valorizar os recursos econômicos de modo que o aluno poderá perceber que não se pode comprar tudo que deseja, e coloca na balança a necessidade assumindo uma consciência financeira que pode ser considerada prioritariamente a necessidade em relação ao desejo, e desta forma enfrentar os desafios do consumismo.

Um dos desafios a lidar é o apelo consumista que a mídia faz o tempo todo. de um lado, há um evidente apelo à construção da identidade social a partir do gasto. Pois o Brasil tem sido displicente ao não preparar adequadamente as crianças para lidar com o apelo consumista.

O dinheiro nos dias atuais foi praticamente substituído por cartões (de crédito e débito). Assim sendo, a materialidade do dinheiro se perdeu. E esse aprendizado sobre cartões e dinheiro deveria começar na família, pois a educação financeira é função dos pais e não da escola (D'AQUINO, 2008). À escola cabe apenas reforçar o que foi aprendido em casa.

Quando se considerar a necessidade, as crianças e adolescentes começam a tomar decisões planejadas e isso é bom para a família e estudos.

A figura dos pais como referência na vida de crianças e adolescentes é fundamental, para evitar o consumismo e os mesmo aprenderem a lidar com as frustrações. A tolerância das frustrações ao longo da infância e da adolescência é 
importante não só para driblar as armadilhas cotidianas do consumo nessas faixas etárias (D"AQUINO, 2008, p. 19).]

A educação financeira para criança e adolescentes deve ser um projeto permanente, não existe idade certa para começar, a necessidade aparece na vida de todos os pais, relacionados a pedidos direcionados aos pais. O principal objetivo de se educar as crianças e adolescentes é pensa-los enquanto cidadãos. É importante destacar os papeis dos pais por meio de conversas e informações sendo complementado posteriormente na escola, pois:

Fundamentos financeiros deveriam ser ensinados desde os primeiros anos
escolares uma vez que este será um assunto que acompanhará qualquer
indivíduo ao longo da sua vida. Além disso, será um dos fatores
preponderantes para aqueles que pretendem gozar de uma saúde
financeira equilibrada e tranquila (KIYOSAKI, 2000, [s/p]).

Ao contrário do que se pensa, a criança entra em contato com as finanças muito cedo. O ser humano começa a compreender finanças, de uma forma mais substancial, por volta dos dois anos e meio de idade

O Brasil tem algumas iniciativas de educação financeira de crianças e adolescentes, no Rio Grande do Sul, São Paulo, Brasília e outros estados. As iniciativas são realizadas por meio de projeto desenvolvido nas escolas. Estudo realizado na Universidade de Brasília criou um aplicativo que auxilia no aprendizado de matemática financeira para crianças e adolescentes baseado em um análise comparativa de aplicativos similares e também na utilização de um framework (i.e. estrutura) que descreve ambientes educacionais interativos digitais para crianças e adolescentes Sob o ponto de vista pedagógico inserir as crianças no mundo da educação financeira na tenra idade permiti que a criança e adolescente aprenda e coloque em prática conceitos como, disciplina e controle, essenciais na diária com o dinheiro.

\section{A Importância do Ensino da Educação Financeira no Ensino Fundamental}

Numa sociedade cada vez mais capitalizada e complexa, a educação financeira é essencial e indispensável na educação. A educação financeira visa levar à alfabetização financeira e motivar as pessoas, principalmente crianças e adolescentes conhecer a importância do dinheiro no seu cotidiano de vida (OCDE, 2014). 
Isso está alinhado com a necessidade de desenvolvimento de currículos educacionais focados na cidadania, que implica em responsabilidade, inclusive em questões financeiras. Mas infelizmente, não existe investimento nos currículos de educação para a cidadania no ensino fundamental e médio. Crianças e adolescentes só podem realizar todo o seu potencial como cidadãos se tiverem poder financeiro e capaz; os blocos de construção a esse respeito são educação financeira, educação social e financeira inclusão.

A Educação Financeira aconteça na escola e comece desde cedo. A educação financeira é a posse de conhecimentos básicos ou competência, e a educação é o meio para construir essa capacidade. A maioria dos programas de educação financeira de base ampla para crianças tentam trazer um conhecimento básico mínimo de habilidades de gerenciamento de dinheiro em relação a compras de materiais lúdico entre outros.

Para investir na educação financeira é necessário que a temática possa ser discutida no sistema de ensino do fundamental ao ensino médio. Assunto que pode ser tratado na disciplina de matemática, pois a mesma relaciona o entendimento coerente com situações cotidianas. $O$ desafio da educação financeira começa no ensino fundamental, principalmente com a matemática. O conhecimento matemático diante da sociedade está entre os poucos gêneros do conhecimento cuja importância não tem sido questionada ao longo da história. Pelo contrário, sempre recebeu reconhecimento e prestígio, pois:

Para os antigos gregos, que buscavam no conhecimento alguma forma de
certeza, a matemática tinha um valor especial. Platão sustentava que o
conhecimento e a certeza estavam ao alcance do ser humano, e a
matemática era o exemplo mais notável disso. Tempos depois, com a
revolução científica, os poderes da matemática ganharam novo formato.
Tornou-se senso comum que as leis da natureza possuem um caráter
matemático (SKOVSMOSE, 2014, p. 19).

Ainda é muito forte em nossa sociedade a visão de que a Matemática possui maior influência no desenvolvimento da inteligência dos sujeitos. O que pode ocasionar medos e dificuldade de aprendizagem, relacionada com a educação financeira.

\section{Considerações Finais}

Ao final desta investigação foi possível perceber a importância e a contribuição do ensino da Matemática Financeira no Ensino Fundamental II para o 
pleno exercício da cidadania com uma concepção crítica sobre como gerir e administrar o dinheiro. Pode-se afirmar que a temática incide que há indicações de que, com relação ao componente da educação financeira na perspectiva da matemática no Ensino Fundamental II podem melhorar os conhecimentos e atitude e consciência de cidadania.

Ou seja, o ensino da Educação Financeira na disciplina de matemática no Ensino Fundamental II pode contribuir para a formação de cidadãos mais críticos a partir do momento que educa o aluno para ser um consumidor consciente com a formação matemática e cidadã ampliando a compreensão das operações fundamentais.

Vale salientar que a Educação Financeira torna-se relevante desde o Ensino Fundamental II para que ocorra de forma mais sistematizada nos livros didáticos e não do modo pontual como atualmente é encontrada. E desta forma poderá oferecer condições para desde o Ensino Fundamental II o aluno possa melhorar a compreensão em relação a conceitos e produtos financeiros; desenvolver os valores e as competências necessários para tomar consciência das oportunidades e riscos das escolhas financeiras; ajuda a fazer escolhas bem informadas e a adotar ações que melhorem o bem-estar, comprometidos com o futuro além de auxiliar a resolver desafios cotidianos, ajudando a realizar sonhos individuais e coletivos.

Dependendo da metodologia aplicada pelo professor de matemática, a aprendizagem da Educação Financeira na matemática pode envolver os alunos em tópicos de seu interesse e oferece oportunidades para explorar como os conceitos financeiros do mundo real.

Os efeitos da Educação Financeira nas crianças e adolescentes são relativamente limitados porque é metodologicamente difícil avaliar o comportamento. Diante de tal abordagem é possível até salientar que os programas de Educação Financeira e matemática podem ser eficazes na redução de endividamento e consumo consciente. Pois ela pode contribuir para a conscientização de planejamento e gestão de renda bem como economizar, investir e afiançar uma vida financeira mais estável, de modo que possa possibilitar reflexões e possíveis mudanças de comportamento.

\section{Referências:}

BRASIL. Parâmetros curriculares nacionais: terceiro e quarto ciclos do ensino fundamental. Brasília: MEC/SEF, 1998. 
CAMPOS, M. B. A educação financeira na matemática do ensino fundamental. Juiz de Fora, [material impresso] 2012.

D'AQUINO, C. Educação financeira: como educar seus filhos. 1 ed. Rio de Janeiro: Elsevier, 2008.

GIORDANO, C.C; ASSIS, M.R.C; COUTINHO, C.Q. S. A Educação Financeira e a Base Nacional Comum Curricular. [s.I.] Revista de Educação Matemática e Tecnológica Iberoamericana,2019

KENSKY V.M..Tecnologias e Ensino presencial e a distância.6. ed. Campinas, SP: Papirus, 2003.

KIYOSAKI, R. T. Pai rico, pai pobre: o que os ricos ensinam a seus filhos sobre dinheiro.. Rio de Janeiro: Elsevier, 2000.

OECD - ORGANISATION FOR ECONOMIC CO-OPERATION AND DEVELOPMENT. Students and money: Financial literacy skills for the 21. PISA. Paris: OECD, 2012

PINHO, T.; CAVALCANTE, M. SANTOS, A. J.; COSTA, R. SANTOS, P. H.; DOS SANTOS, D. Educação financeira e formação de cidadãos conscientes: prática de extensão universitária no ambiente escolar. Santa Fé: Congresso Iberoamericano de Extension Universitaria, 2011

SAVOIA, J. R. F; SAITO, A. T; SANTANA. F. de A. Paradigmas da Educação Financeira no Brasil.. Rio de Janeiro; RAP, 2007.

SILVA, A. M. Uma experiência de Design em Educação Matemática: 0 Projeto de Educação Financeira Escolar. Rutgers/New Jersey/EUA, Newark, 2011.

SKOVSMOSE, O. Um convite à educação matemática critica. Campinas, SP: Papirus, 2014. 